\title{
Griping and joking as identification rituals and tools for engagement in cross- boundary team meetings
}

\author{
Vanessa Pouthier \\ The University of Melbourne, Australia
}

\section{Corresponding author:}

Vanessa Pouthier, Department of Management and Marketing, The University of

Melbourne, 198 Berkeley Street, Level 10, Parkville, VIC 3010, Australia.

Email: vpouthier@unimelb.edu.au 


\title{
Griping and joking as identification rituals and tools for engagement in cross- boundary team meetings
}

\author{
Abstract \\ This article explores the role of griping and joking behaviors in cross-boundary \\ teams. Those socio-emotional behaviors often go unnoticed in studies of team \\ communication, as does more broadly the work of building relationships. Given the \\ growing recognition that the quality of connections among team members significantly \\ influences the quality of coordinating and knowledge-sharing practices in cross-boundary \\ teams, this seems an important lacuna to address. Drawing on a qualitative study of a cross- \\ occupational team responsible for palliative care and oncology patients, I illustrate how \\ those mundane, recurrent communicative activities, which may appear tangential to the task \\ at hand, have important relational and emotional consequences for the functioning of cross- \\ boundary teams. Based on the observed characteristics and effects of a variety of griping \\ and joking behaviors, I propose to conceptualize those communicative activities as \\ identification rituals. I discuss the implications of this work for both research on the \\ production of positive relational realities in cross-boundary teams and the study of \\ organizational griping and humor.
}

\section{Keywords}

Cross-boundary teams, team engagement, griping and joking rituals, healthcare 


\section{Introduction}

Organizations increasingly rely on cross-boundary teams, involving members from different organizational units or different occupations, to enhance learning and performance in ever more complex and competitive environments (Pinchot \& Pinchot, 1993). Crossboundary teams are frequently used to coordinate activities between different departments and functions, to improve the quality of existing products and services, and to develop new ones (Oborn \& Dawson, 2010; Edmondson \& Nembhard, 2009).

Scholars have long stressed the importance of the team's affective and relational context in supporting the realization of the theoretical benefits of team-based organizing (Cronin \& Weingart, 2007; Gittell, 2006; MacPhail, Roloff \& Edmondson, 2009). A number of studies have documented for example the positive role of collective team identification and trust among team members in facilitating constructive, synergistic team dynamics across divisional or occupational boundaries (e.g. Mitchell, Parker \& Giles, 2011; Van der Vegt \& Bunderson, 2006). This naturally triggers questions regarding the mechanisms capable of fostering the development of those positive emergent team affective states.

Recent research recognized the importance of team leaders' symbolic work in supporting the salience of a team identity (Lindenberg \& Foss, 2011; Heaphy \& Dutton, 2008) and in establishing an inclusive context that facilitates trust and team psychological safety (Nembhard \& Edmondson, 2006). Faraj and Yan (2009) noted the importance of team-based symbols and homegrown rituals that recognize and celebrate team progress. 
Research on cross-boundary teams has so far overlooked the potential import of mundane communicative activities such as playful talk and troubles talk, despite their well-known relationship-building and maintenance function (Ellingson, 2003).

In this article, I explore and theorize the role of griping and joking behaviors in cross-boundary teams, drawing on a qualitative study of a cross-occupational team responsible for palliative care and oncology patients. Griping and joking behaviors were not initially part of my research design; their significance emerged through observation. Using detailed field notes and interview data, I document the typical patterns of griping and joking behaviors and their associated bodily and emotional dynamics in team meetings, provide a typology of forms of griping and joking based on their object, and highlight their perceived individual and collective effects.

The findings uncover and illuminate the critical role of these seemingly mundane behaviors for cross-boundary work, supporting and elaborating the well-documented observation that complaint and humor can positively influence the quality of connections in the workplace. Fundamentally, the study contributes a view of griping and joking behaviors as identification rituals in cross-boundary teams. Through the performance of griping and joking rituals, team members can make both a common identity and distinct occupational identities salient in team interactions, and thus create transient embodied and energizing bonds of mutual affinity and respect, which can support team engagement.

My work thus contributes to our understanding of cohesion building in crossboundary teams by exposing griping and joking as critical and distinct mechanisms through 
which much needed socio-emotional bonds may be produced and reproduced. It also contributes to scholarship on complaint and humor by further specifying the processes through which griping and joking achieve their cohesive effects. In particular, my work highlights the role of the body and affect in the identity work accomplished through the rituals. I also identify in certain rituals' ability to foster tolerance and appreciation of differences a new route towards relational quality.

The article opens with a review of the literature on griping and joking in teams and organizations. Then, the empirical context, data and methods of analysis are described, followed by an analysis illustrating the varied forms that griping and joking take and the various functions that they play in the context of cross-boundary teams. After a discussion of the study's main findings, the article concludes by outlining its contributions to both work on the development of positive relational realities in cross-boundary teams and the growing research stream on joking and griping in the workplace.

\section{Theoretical Background}

Griping, the act of expressing dissatisfaction or frustration about someone or something (Kowalski, 2002; Boxer, 1993), and joking, the act of engaging in social and communicative behaviors that are perceived humorous (Martineau, 1972), are a routine part of everyday group and organizational life; yet those communicative activities were for a long time considered tangential to the real work of organizations and thus given little serious academic consideration (Westwood \& Johnston, 2013). Growing interest in the emotional and paradoxical nature of groups and organizations has provided ground for a 
stronger research agenda ${ }^{1}$ on those distinct but related communicative behaviors and the important and complex functions they play in the workplace.

Both griping and joking are symbolically charged, emotion-invoking activities that invite responses from their audience. While both are entrenched in the domain of casualness and triviality, they differ significantly in terms of their dominant affective key (Katriel, 1985). Through joking or the exchange of humorous lines oriented towards a common theme, organizational members signal amusement to one another. The key that prevails in conversational joking is that of playfulness and mirth. Through griping or the exchange of plaintive and commiserative lines, organizational members communicate displeasure or annoyance with a past or ongoing action or situation, and here the key that prevails is that of plaintiveness and frustration. Griping primarily invites commiseration; joking invites laughing along. However, some scholars have noted how functionally comparable both communicative activities are (e.g. Gabriel, 2000).

Griping and joking are most obviously known for their psychological "tension relief" function (e.g. Kowalski, 2002; Robinson \& Smith-Lovin, 2001). Both communicative activities have been likened to "troubles talk" or the sharing of stories of situations that have caused or are causing some discomfort. Griping and joking allow the relief of pent-up tensions and frustrations. Employees use jokes and gripes to manage the emotions associated with the stressful and difficult circumstances they regularly encounter at work, such as closeness to death and suffering in medical settings (Coombs \& Goldman 1973), the tediousness of work and stress-inducing organizational norms on shopfloors or in banks' back offices (Collinson, 1988; Weeks, 2004), or the endemically contradictory 
nature of one's work role or one's workplace practices (Hatch \& Ehrlich, 1993; Rodrigues \& Collinson, 1995). Griping and joking provide important coping mechanisms through which employees can mentally disengage and emotionally distance themselves from the troubling or threatening situations that come with their job.

Beyond their overt, ventilating function, griping and joking also have important social functions. The literature repeatedly suggests that both communicative activities are especially important in creating and sustaining social cohesion and a sense of community (e.g. Fine \& DeSoucey, 2005; 2004; Weeks, 2004). Griping has been described as "a glue that strengthens the bonds between the individual and the group" (Weeks, 2004, p.67) and as an important interactional resource for generating solidarity (Katriel, 1985) by allusion to or dramatization and reaffirmation of shared troubling circumstances. Similarly, joking has been recognized as a key strategy for building social cohesion (Cooper, 2008; Seckman \& Couch, 1989) and maintaining relationships in groups (Robinson \& Smith-Lovin, 2001), with humor and laughter functioning as invitations to come closer or reaffirm social bonds of belonging (Coser, 1959) or as signals of trust and solidarity (Terrion \& Ashforth, 2002).

Griping and joking can also play a key role in conflict management, by reducing the face threats of criticisms (Marra, 2007). Joking permits interaction to proceed without public disharmony, by allowing the expression of differences without damage to the parties' identities and relationships (Fine \& DeSoucey, 2005). The ambiguity inherent in humorous remarks allows interaction partners to distance themselves from any one particular meaning; the partners can all laugh along for different reasons, and the appearance of unity rescues the interactions from discord (Hatch, 1997). Griping similarly 
can reveal differences of opinions without generating embarrassment or division, when norms of tact and discretion prevail (Weeks, 2004). Complainants often hint at, rather than clearly state, negativity.

Both the affect regulation and relationship building and maintenance functions of griping and joking may be especially useful to cross-boundary teams. Such teams have been depicted as high-stress environments, in part due to the complexity and uncertainty surrounding their tasks, and as contexts that both crucially need social cohesion and a sense of we-ness, and present critical challenges to the development of those much needed group affective states, such as strong ties to divisional or occupational subgroups with distinct perspectives and priorities (Edmondson \& Nembhard, 2009) and status differences between subgroups (DiBenigno \& Kellogg, 2014).

My research aim is to shed light on the role of griping and joking in cross-boundary teams, a previously unexplored phenomenon. I propose to identify the particular forms of griping and joking that team members use in team meetings and their consequences. This study builds upon the existing literature on griping and joking behaviors in the workplace, much of which has determined that the activity and functions of complaining and humor are context dependent (Korczynski, 2011). It adds the unusual context of cross-boundary teams to the body of knowledge, and in doing so further articulates the processes through which griping and joking achieve their cohesive effects. Past research has indeed established that griping and joking can partake in the development of relationship quality in dyads and teams, yet the mechanisms through which these mundane communicative behaviors have these effects require further unpacking (Cooper, 2008; Romero \& Pescosolido, 2008). 


\section{Methods}

Research setting and participants

This study draws on observations of team meetings and interviews made over a year on the palliative care/oncology unit of a large hospital in the Midwest of the United States, where dying patients, patients with life-limiting conditions and cancer patients are admitted for, respectively, the management of medical complications and acute care symptoms, and cancer treatment and pain management. Federal guidelines, recognizing the benefits of joint working among physicians, nurses, social workers, case managers and spiritual care providers to address the complex nature and demands of palliative care, require regular team meetings where these various occupational groups can communicate and collaborate. While palliative care may represent an area of care where cross-boundary teamwork has evolved to a greater extent than in more traditional medical areas, effective integration of team members' diverse perspectives and coordination of their activities do not always take place (Wittenberg-Lyles, 2005).

The team observed initially included five part-time attending physicians, three nurse practitioners, two nurse managers, twelve inpatient nurses, two pharmacists, a homehospice care coordinator, two social workers, one case manager, and three bereavement counselors. Rotating residents and medical students were also part of the team. The team was later extended to include diverse practitioners from the oncology/hematology services after the merger of two co-located units' nursing staffs. While some team members were interacting with one another throughout the day, the weekday formal meetings really were 
what brought material consistency to the team. Each discipline sent a representative to the meetings; membership was fluctuating from one meeting to the next with the case manager, one of the social workers and the hospice liaison being the only members present every day. Overall, seven to ten team members were attending the entire 45 - to 60 -minute meeting, while five to eight inpatient nurses took turns at the table, staying ten minutes on average. Typically, the nurses initiated the care planning conversation by sharing key biomedical information and updates and raising potential issues of various types. Team members were encouraged to add information as they saw fit and to jointly create plans that identify salient problem areas and actionable interventions. Up to 36 cases were discussed each morning.

The occupational representatives brought different perspectives in relation to the patients and different interests to the meetings. Physicians and nurse practitioners, working closely together, typically focus on the biomedical aspects of the care plan. They look at the facts of patient cases - the biomedical details that define, explain and inform treatment of the disease or symptoms - and form expert decisions regarding the best treatment options. Social workers and spiritual care providers focus their attention on the patients' broader socio-emotional context, and bring reflections on care and non-medical issues to the table. They seek to improve the quality of life of the "whole person". Staff nurses focus on both objective clinical facts and patients' subjective experiences, advocating on their behalf. Case managers are responsible for identifying and coordinating the post-hospital needs of patients, with social workers supporting them in that role, and for facilitating timely and appropriate discharges from the hospital according to patients' levels of acuteness and 
insurance status. Hospice liaisons facilitate hospice admissions and care management for hospice patients who are in the hospital. Both the location of the palliative care/oncology unit in an acute medical center and the merger with the medical oncology/hematology unit add complexity to the diversity of expertise and role responsibilities described above.

The cross-boundary team on the unit faces many of the challenges to team engagement that scholars of cross-boundary teamwork have identified. The team did not exhibit clear and precise boundaries. There is a small set of core members; but the team is more like a network of diverse healthcare professionals, a different subset of which recombines and meets every day around patient cases to address multiple goals with minimal managerial oversight. Besides, team members dedicate only a small amount of their time to cross-disciplinary coordination and problem-solving, activities for which they are not organizationally rewarded. This cultivates tighter affinity with their respective occupational communities than with the cross-boundary team. Also, the challenge of differences in perspectives and priorities is always present in the team, with team members encouraged professionally and/or organizationally to construct the patients in diverse, and potentially conflicting, ways and to prioritize different goals. Such diversity can trigger occupational identity-related anxiety and conflict, which power and status differentials between members may further compound (DiBenigno \& Kellogg, 2014; Mitchell, Parker \& Giles, 2011). In addition, the team faces high levels of stress, stemming from heavy workloads, the complexity of patient care, proximity to death, and organizational pressures to meet high performance standards. Finally, the team had no obvious social scaffolding to 
help configure the team practices, reduce complexity, and thus enhance a common identity or culture. The team had no leader and the goals were not clearly stated.

\section{Data collection}

The data comprised: (1) observations of naturally occurring communication in 50 weekday ITD meetings, (2) 16 initial semi-structured interviews with team members to explore the perception and management of differences and conflict in the team, and (3) 6 follow-up interviews to deepen the griping and joking themes that emerged in the first phase of data collection and analysis. During the meetings, I took extensive field notes, emphasizing verbatim discourse and emotional displays, to capture the style, content and mood of social interaction. I functioned primarily as an observer, asking questions only when the meetings were over. As mentioned earlier, the care planning meetings were one of the few locations where team members interacted with one another. Beyond their objective instrumental function as tools for coordination and problem-solving, the meetings provided a structural opportunity for performing relational work "in the guise of discharging business or work" (Schwartzman, 1989, p.78), making it an ideal context for studying symbolic practices and processes.

In addition, I interviewed two physicians, two nurse practitioners, two nurse managers, five inpatient nurses, a pharmacist, a physical therapist, the home-hospice coordinator, a social worker, and the case manager. The resulting sample was one of convenience, but an attempt was made to include team members from different disciplines. The interviews were scheduled during work time in an isolated office; each lasted from 30 
to 45 minutes. Questions in the initial interview protocol revolved around the participants' relevant contexts, their backstage interactions with one another and principally their perceptions of and attitudes towards the meeting dynamics. The follow-up interview protocol targeted attitudes, thoughts and experiences with griping and joking. Besides attendance at IDT meetings and formal interviews, I interacted with the Director of Oncology Nursing and the Unit Nursing Manager to get a better sense of the general organizational context of the meetings. I also participated in two oncology/palliative care workshops, one support group meeting and two nursing staff meetings to better understand life on the unit.

\section{Data analysis}

I began the investigation aiming to understand how members of cross-boundary teams surmount their differences in problem-solving situations, but open to alternative frames and insights. I initially looked for evidence of conflict, interpersonal acts of negotiation/conflict resolution and boundary work in the meetings. An obvious sense of kinship among the team members and the team's overall group efficacy rendered the observation and analysis of conflict among occupational subcultures and its management difficult. Boundary work was subtle. As I was gathering and successively reviewing more and more data (Glaser \& Strauss, 1967), I shifted my focus of observation to the group's ritualistic practices, whose enactment I suggest helped strengthen the team bonds and potentially contained overt conflict. Among the mundane and ongoing rituals of expressive interaction identified in the meetings (Handelman, 1976), griping and joking stood out by their frequency of occurrence and their likeness in terms of structural organization around 
sources of trouble. A couple of participants had also identified them as a key differentiating factor between energizing and draining meetings. I conducted follow-up interviews with six of the participants to deepen and triangulate my understanding of the relational impact of joking and griping based on my field observations with insights into the team members' subjective experiences.

I marked all the incidents of griping and joking I could identify in the mass of data "on the basis of paralinguistic, prosodic and discoursal clues" (Holmes, 2000, p.163). Griping and joking episodes are distinguishable by their dominant key. Griping cycles are primarily characterized by a tone of plaintiveness and frustration, accompanied by a sense of entrapment in the event itself (Katriel, 1985); while the principal key in joking episodes is one of amusement (Holmes, 2000). Griping and joking cycles of varied length and intensity happened both in the opening and transitional phases of the meetings (when participants waited for or welcomed the next nurse to the table) and in the serious discussions of specific patient cases. Constant comparison (Glaser \& Strauss, 1967) of the form and content of those sequences and "double fitting" between theory and data (Ragin, 1994) suggested that griping and joking cycles, in their varied expressions, worked as interaction rituals that supported team engagement through two primary routes: the construction of the commonalities that unify the team members, and also the subtle staging and accommodation of their differences.

Below I present in turn the key forms of griping rituals and joking rituals I identified in the team meetings, while systematically highlighting the affective and relational functions each form plays. Each form, recognizable by the target and style of 
either the griping or joking cycles, is illustrated by a typical "little drama;" and their respective and joint effects are supported by observational notes and interview quotes as they emerged from my cumulative analytical memos. All the examples presented here are reconstructions of actual interactions, in which I tried to recall the participants' exact words and expressions as closely as possible. The coding of the additional, more general data collected during the meetings and the interviews provided important background information for the current analysis.

\section{Findings}

After only a few weeks of observation, I was struck by the pervasiveness of griping and joking behaviors in the meetings and it seemed important to investigate the part they were playing in team interactions. Griping and joking rituals came in different forms and supported team engagement in various ways, which, though unique, could be categorized into two broad types of rituals: those that foster an energizing sense of connection through the construction of commonalities across team members, and those that facilitate engaged interactions through the productive focusing and handling of occupational differences. Before detailing the key forms of griping and joking in the meetings and addressing their respective and joint affective and relational consequences for team interactions, I briefly discuss the essential interactive, public and referential qualities of these communicative practices. 


\section{General considerations}

All the episodes of griping and joking identified during the meetings involved some form of interaction. In fact, I could have hardly located many humorous remarks if it were not for the laughter, giggles or smiles that followed them. Nor could I have noticed many gripes without the commiserating reactions they triggered. Laughter and commiseration of course were not the only possible responses to a humorous or plaintive comment, but almost always response there was from at least one if not all the team members present, in both verbal and nonverbal forms. The extract below exemplifies the interactive nature of griping in the meeting as well as the use of nonverbal cues to project frustration with a situation constructed as problematic.

Nurse (looking as if the sky is about to fall on her head) - The family is...well... Advanced Practitioner (in a sympathetic tone) - Let's say complicated. I'm very sorry.

Social work (grimacing and nodding) - I second that. They're challenging.

Care coordinator (patting the nurse on the shoulder) - We'll help you.

\section{[Laughter]}

This series of contiguous venting and supportive verbal and nonverbal statements constitutes a griping cycle; similarly a humorous statement followed by laughter and/or additional joking remarks comprises a joking cycle. The humorous comments and complaints were most often expressed loudly and clearly, as if they were invitations to all 
the team members to share in, rather than egocentric statements. The sitting arrangements rendered the speakers' facial expressions and/or bodily actions quite visible to the observers as the messages were delivered.

The joking and griping exchanges I observed centered on recurring topics. The team members for example often griped about the primary care teams, with whom they were frequently disagreeing as to the best course of action for patients. While discussing specific patient cases, team members would regularly launch into a griping session about the futility of certain treatments and the need for 'goals of care' discussions. Relatedly, they repeatedly joked about the need to "clean up" patients once transferred to their services. Those recurring episodes signal a dialectical tension between the biomedical and (bio)psychosocial approach to end-of-life care. The next two sections on griping rituals and joking rituals will provide more details on the recurring themes that team members drew upon. The important point here is that in the course of ongoing interaction in specific team meetings, team members engaged in similar types of griping and joking, with recognizable themes across meetings, contributing to the creation and maintenance of a set of joking and griping references.

\section{Griping rituals}

In the care planning meetings, team members regularly, even if briefly, talked about problems, feelings, and/or specific events that were troubling them. Participants agreed that the meetings were not an appropriate forum to vent about deep issues, but recognized that they could serve a support function. Griping rituals took many forms: they had various 
objects and various structures and tonalities. Team members regularly complained and commiserated in a mild tone about the difficult working conditions they jointly faced, mostly workload-related issues. They also griped about challenging patients and families, while often excusing the challenging behaviors. The most intense form of griping targeted members of the extended network of healthcare providers taking care of oncology patients, who were not present in the meetings. They were especially critical of certain physicians. They also at times excused the practices and decisions of primary care teams while complaining about them. I will discuss these various forms of griping rituals in turn, highlighting their affective and relational functions.

Challenging work conditions. A fairly common form was simple griping cycles that referred to the challenging work environment in which the team members all operate. Team members repeatedly commented together on how overworked and stressed they were, as can be seen in the following interaction between a social worker and a nurse at the end of a meeting:

Social worker - We've been really hectic in here lately, my day off last week felt so great.

Nurse (rolling his eyes) - Don't tell me! Happy to escape the craziness soon. Wanna hear my plans?

They both smiled at one another and sighed.

Caregiving contexts are often portrayed as hectic and stressful. Burnout is a significant risk in palliative care and oncology care environments, as healthcare 
professionals are facing most immediately the proximity of death, in addition to the bureaucratic pressures of the modern hospital. No matter what their occupational role, participants all expressed concerns about workload schedules. In the griping episode described above, the nurse quickly acknowledged and validated the social worker's feelings that the unit had been especially busy recently, before trying to break the mood with a jocular reference to escape plans; signaling in the process that he and the social worker are experiencing similar difficulties at work.

Through such relatively short complaining/commiserating cycles, team members not only externalized their feelings of frustration, but also developed a sense of we-ness. The rituals in the expression and synchronization of emotive displays of irritation and weariness linked the participants together in camaraderie of exposure to similar work stressors. A nurse commented that "it makes [them] feel not alone, knowing that [others] are experiencing the same thing." Griping rituals bring to the forefront of team members' attention the existence of a community of shared fate, whose members face on a daily basis similar constraints and frustrations. As will be discussed later, venting about working conditions could also be done in more humorous and lighthearted tones.

Difficult clients. Team members also regularly griped about challenging patients and/or families, another common source of stress in the daily work of healthcare professionals. During case discussions some participants confessed to feeling frustrated at the behavioral challenges that a patient or their family posed, and received in turn positive, verbal and/or nonverbal feedback from other team members, as in the following example: 
Nurse (hesitant) - I'm having some difficulties with the family.

Social worker (rolling her eyes) - I had a meeting with them last week and they drained me of all my energy.

Other team members offer sympathetic nods.

In this brief episode, team members validated the experience and feelings of the nurse, as she had to deal with a particularly demanding family. They signaled that they too were struggling with that particular family or knew what it meant to face a difficult family.

An interesting and frequent extension of the simple griping interacts about challenging clients consisted of lengthier cycles, involving not only griping and supportive statements, but also exculpatory statements. When talking about incidents with patients or families, team members often excused difficult behavior by locating it within the patient's 'illness or dying trajectory' or the family's coping trajectory, as can be seen in the following interaction:

Nurse (visibly upset) - The niece has been yelling at us every single time we entered the room this morning. I don't think that there is anything we can do better but I do not need anyone else beyond my patients to scream at me. She said her aunt hasn't got any medicine in at least an hour, when her aunt was obviously screaming out of pain. First off, it's hard to believe that we would not have done anything given the circumstances. She's obsessed.

Care coordinator (shaking her head) - Yes it's getting very unpleasant out there. 
Hospice liaison (in an understanding tone) - It is an outlet for them.

Nurse practitioner - Should we think about another method of administering the pain medication?

Hospice liaison - Cannot we program the PCA pump?

Care coordinator - It's not safe; we would need to stay in the room.

Case manager - Can't we have two machines?

Care coordinator - Good thinking but we'd still have to switch to the old way and be in the room. The standards of practice for that other machine are different.

Case manager - If it is policy, we cannot indeed go around it.

Care coordinator - Also I worry that switching will be a red flag for the family.

Hospice liaison - Definitely, they'll be thinking: 'Why haven't they done that before? It could have spared our aunt some excruciating pain.'

Nurse practitioner - I'll call the niece.

Social worker - It is easier for people to be angry than sad.

In this episode, the nurse called attention to the aggressive and controlling behavior of a patient's family member. The team members not only offered a validation statement and some suggestions for better pain control (themselves problematic given staffing levels 
and the hospital's safety policies), but also placed the family member's troubling and disruptive behavior within a forgiving framework.

In addition to performing the camaraderie of exposure to similar work stressors discussed previously, the team members here also engaged in collective emotional editing and brought forward their shared moral identity as caring and emotionally controlled professionals as they reconstructed the family member's aggressive behavior as situationally warranted deviance and re-established composure through the ritual. The hospice liaison observed that "sometimes just hearing that other people are experiencing the same struggles can help to validate the feelings that you're having so that you don't internalize them and feel like 'I'm not being professional."' Losing self-control is unprofessional, even more so in end-of-life care where performing professional niceness is seen as integral to the care of the terminally ill patients ( $\mathrm{Li}, 2004)$. In re-affirming this central and shared value of professional niceness, the griping rituals can help the team members feel closer to one another, despite differences in occupational roles and priorities. The unit's nursing manager believed that the biggest potential value of the meetings lay in the fact that they provided nurses with the opportunity to see that nurses and doctors had similar feelings.

'Outside' professionals and teams. The rituals of venting general frustration and moaning about difficult clients were rather mild in tone. The team members used tonalities and language that sounded more upset when grappling with the challenges presented by the practices and decisions of certain practitioners who were involved in the care of their patients, but were not part of the team. A recurring source of griping in team meetings was 
the decision by oncologists to pursue aggressive treatment in dying patients and their reluctance to start "goals of care" conversations with patients with poor prognosis. To illustrate:

Nurse (moving on to the next patient's file) - Oh my god! Mr. William, room 1678, DNR. The primary team is keeping him on antibiotics...

[The nurse practitioner and the physician nod and grimace, seemingly anticipating what is coming next]

Nurse (displaying skepticism and frustration) - He was confused and then totally unresponsive yesterday. Nothing came up from the additional tests they did lately. I offered them to consult with palliative, but they're not...

Case manager (displaying first understanding for the primary care team's decision, then empathy for the nurses and agreement with the nurse' assessment) - Well, the patient has been having ups and downs for quite a while now you know - but I agree he has had pretty bad downs lately where the nurses could not even tell whether or not he would make it through the night; and he's very lethargic today.

[Everyone in the room seems upset by the situation; they exchange looks around the table as if to get their feelings validated]

Physician (looking at the nurse) - Do we know who's the attending? Don't tell us, I am sure we can guess. 
Chaplain (visibly frustrated) - Who is going to call her? Really I'm tired of this. It's ridiculous.

[Many team members nod without verbally escalating the criticism]

Nurse (in a much lighter tone) - Yeah, she can be unreasonable sometimes!

In this episode, team members projected frustration with a situation constructed as problematic: the continuance of antibiotic therapy, often considered an element of aggressive, intensive care regimens for life prolongation, in a patient perceived as actively dying. They also singled out one physician, who has a reputation for systematically avoiding 'goals of care' conversations with patients and families and pursuing lifeprolonging strategies no matter what the circumstances.

Such collective acts of griping both reveal and revitalize shared sentiments and beliefs regarding the moral value of the biopsychosocial model of patient care that team members have been socialized to embrace (against the biomedical model still prevalent on most hospital wards), and the importance of being open to receiving alternative perspectives from other professionals. By criticizing other professionals' practices and decisions, the team members define for themselves and their observers what they believe is valuable and right. Participants expressed on multiple occasions that "[their] whole system is wrong" and that they "often have to work behind the scenes, it does feel bad." The griping rituals, even as they reveal their common lower status in the system, constitute a challenge to that system. A participant commented that they might "give the nurses the confidence to talk to the other areas' doctors." 
An interesting variation in sessions of collective griping about other professionals not present in the room was the presence of justificatory turns. When griping about other teams' behaviors, some team members would at times downplay the criticism by rationalizing the behavior.

Nurse - Admitted for fever; he's not quite actively...well he's sleepy but alert. The team thought he would be actively dying today but he is more alert even though he's not responding.

Physician (in an impatient tone) - So what are the goals?

Nurse - They plan on giving him more steroids.

Physician (showing frustration) - They need to start building the support!

Hospice liaison - Yes, they can't just stall.

[Other meeting participants shrug.]

Nurse - I know. I think it's just what the family wants. Right now the team is focused on making sure he is comfortable. The patient has just been deteriorating between hospital stays.

Physician - He's been in and out a couple of times now. It's time.

Nurse - I know .

In this episode, the physician initiates a griping session about the primary care team's reluctance to have a "goals of care" conversation with the patient and his family. 
She receives verbal and nonverbal support from team members. However, the nurse while agreeing with the physician is also excusing the primary care team's behavior, by stressing both the alertness of the patient and the family's wishes and also presenting steroids as a comfort measure (consistent with palliative care goals) rather than a life-prolonging measure. She encourages the team members to construct the practitioners' seemingly troubling actions as understandable and forgivable.

In this type of ritual, team members express different opinions about what the other team is doing. By juxtaposing rationalization to condemnation, they are performing ambivalence, and the negative evaluation of the oncology team's behavior is attenuated. A physician observed that "it takes patience; patience on the part of the hospitalists and the palliative care team because often the oncologists are struggling and we need to be aware of that." Also, the differences of opinions about other teams' behavior may reflect differences of perspectives and priorities within the team, even as their ritualistic juxtaposition promotes understanding and patience. The case manager found it interesting that the team members never truly questioned openly what they themselves are doing: "Now the interesting thing is it is easy to ask that as an outsider but more difficult when it's your own case." Glossing over conflicting goals is often easier than engaging in "honest and open conversations" or directly confronting differences.

\section{Joking rituals}

In addition to regular griping sessions, the team members also frequently engaged in communicative behaviors intended or perceived to be humorous during the meetings. 
Effectively those humorous exchanges, just like griping rituals, found their source in some troubling aspects of the team members' experiences in the unit. They too took on many distinctive forms, targeting various objects and drawing on different tonalities. Overall the tonalities remained more light-hearted and less chagrined than with griping (Gabriel, 2000). Team members made light together of their challenging work conditions. They dealt with difficult patients and families in a jocular tone. They mocked the team's expertise and status. They teased each other about particular aspects of their respective occupational roles. And they playfully challenged the traditional status hierarchy. I will discuss each of those various forms and elaborate on their functions.

Challenging work conditions. Team members would not only gripe but also laugh at their difficult working conditions, each day feeling busier than the preceding one. To illustrate:

Advanced practitioner (glancing at the patient list) - We've got a full house!

Hospice liaison - Hey, anyone working here'd better love full houses!

[The whole audience laughed in return.]

In this episode, the team members made light together of the stressful aspect of working quasi-permanently at maximum capacity. They shared in the perception of what is typical for the unit, workload wise, and stressed the need for resilience and passion in that type of environment. 
Through such joking cycles, team members create social relationships of camaraderie through the reciprocal sharing of (and triumph over) working conditionsrelated anxieties. They signal that they are exposed to the same work stressors, but they do not let those bring them down. Instead, they create a positive emotional atmosphere of support that can contribute to their resilience. A care coordinator stressed that joking can make you "feel like you have a connection to someone else and help you feel more like camaraderie."

Difficult clients. It was also typical for the team members to laugh at the unreasonable or disruptive behavior of a patient or a family member, as can be seen in the following example:

Advanced practitioner - Ah, Molly, the favorite.

Hospice liaison (to the nurse) - Don't deny you love her!

Care coordinator - She's been better (attitude wise).

Nurse (jokingly) - Have you been here lately?!

[Hearty laughter in the audience.]

[The nurse then asks the team for further information. The hospice liaison says that everything is set up for the patient to go home today. The advanced practitioner says she doesn't have an update.]

Hospice liaison - The plan has changed, the patient will spend one week home and agrees to then go to a nursing home. Big change. 


\section{[Expressions of surprise in the audience]}

Care coordinator - See, she has changed! She has gotten better.

\section{[Laughter in the room.]}

In this episode, while sharing information on the case, the team members jokingly and collectively constructed a patient as challenging. Multiple team members participated in dramatizing the whole situation and found amusement in it, signaling that they all had individually experienced the patient as someone "very needy" or if not, they had at least experienced similarly frustrating cases.

Through joking rituals, team members can make visible a community of shared experiences and affect. The care coordinator commented that "it can feel like we're a group, we're in this together" when everyone can relate to and enjoy the jokes. The social worker added that this form of joking also helps the team members muddle through: "because we deal with so many very difficult families, and patients, and very serious...illnesses and situations that it's kind of a way to make it all a little lighter for us, I think, so we can keep doing the work." It is a shared tool of occupational coping, which preserves endurance through adversity.

Team expertise and status. Team members also mocked their own team's expertise in brief joking/laughter interacts. Many of my informants remarked on a positive evolution in attitudes towards palliative care, but still found it difficult to obtain a broader mandate to practice within a medical world that prizes science and control because of the perceived amorphousness of their expertise and their localization within the temporal boundaries of 
end-of-life care. It was not uncommon that their advice be discounted. The team members found in these ambivalent images of themselves held by others resources for self-mockery, as can be seen in the following examples:

Nurse manager - Let's move on to the next case.

Pharmacist (raising his arms in the air) - Oh no. Five more minutes and we could have cured a cancer!

\section{[Laughter in the audience]}

Case manager - There has not been any decision making on anybody's part.

Hospice liaison (with a wink) - Since when is decision-making our strength?

\section{[Laughter in the audience]}

In both instances, the butt of the joke is 'we'. In the first example, the pharmacist invited the team members to laugh together at their inability to cure, and to thereby distinguish themselves from heroic and mechanistic medicine. In the second example, the hospice liaison questioned their ability to make decisions in a jocular tone, triggering immediate laughter from other team members. The joking interact reflects both the challenge of making decisions in conditions of high uncertainty and ambiguity, and the team members' acceptance of uncertainty and ambiguity, when medical culture still focuses on certainty and control.

These joking rituals call attention to some of the team's essential and distinctive attributes, which are not highly valued in the current system (Hibbert et al., 2003). The 
team members, by mocking the indeterminate, artistic components of their own expertise, were turning the stigma on its head and displaying collective resistant pride. Putdowns of common identities (e.g. palliative care workers) can help mark a group's defining characteristics and signal to the group participants that they can laugh at their shared reputation (Terrrion \& Ashforth, 2002). Staging stigma might then just be another ritual by which groups enact commonality of experiences, values and feelings, and as such, it can mobilize constructive energy and help produce a sense of belonging.

Occupational roles. Team members also sometimes humorously teased each other about aspects of their respective occupational roles. The case manager, whose responsibilities involve managing lengths of stay and maximizing reimbursement for the hospital, a source of discomfort in the team, was a frequent target of playful taunting. To illustrate, giggles and laughter followed a nurse's sarcastic exclamation one morning that "Rebecca (the case manager) is the person to PLEASE here!" as the team was inquiring into possible barriers to discharge. The social worker observed:

It's really out of respect I think! They pick on her because they know she needs to get people out of the hospital. And so they like tease her, like "close your eyes Rebecca" or like "don't listen to this Rebecca" you know they make kind of comments like that but I think it's... and I think the way she receives it too is that she is respected and they know that she is going to be on the case, so (laugh).

The case manager confirmed: "most of the time I do not take it personally. It's a pressure valve release...it's not meant to be degrading. I know I've made some comments 
myself!" She represents an easy proxy for a set of goals and activities that many team members still find difficult to integrate within their own frame of reference for action, even as they understand their raison d'être: "it's a reality we have to deal with; I would rather not have to shoot people out or even have to talk about that stuff, but we cannot get around it."

Team members also regularly teased nurses about their inability to resist the call of the ward. Nurses were often late at the team meetings and left them swiftly; they also regularly answered their pagers and made calls during the care planning discussions - all behaviors that constituted resources for teases.

Social worker (calling the nurses) - I'm afraid they will all show up at the same time

Advanced practitioner - I can promise you that it won't happen!

\section{[Shared laughter]}

Chaplain (as the first nurse comes in) - Do it quick before the world arrives!

Nurse (smiling, overly apologetic tone) - I apologize on behalf of our nursing staff.

\section{[Shared laughter]}

In this episode, the team members signal their frustration with the nurses' behaviors, which could undermine the value of the immaterial labor accomplished in team meetings. They also implicitly construct an image of the nurse as someone whose conception of productive time is different from their own. The nurses still perceive their priority to be spending time with the patients. For some of them, the meetings themselves, 
i.e. talking work, were hardly regarded as doing work. The case manager deplored that collaborative talk was not more valued outside of the meetings.

Role-oriented teases reveal differences in responsibilities and priorities, which can be a source of tensions in the team. Joking gives the team members an outlet for the stress and frustration that the occupational roles, responsibilities and preferences of others may induce. It enables some team members to express their wish that they would rather not think about utilization issues and work without bureaucratic constraints, or that they would like everyone to prioritize collaborative talk. It allows them to communicate those wishes and the implicit criticisms they carry in an indirect, non-threatening way. A care coordinator observed that she does not respond well to complaints and explicit frustration, that "it makes [her] frustrated because we are all trying our best." Teases thus allow the maintenance of working relationships with others. They also demonstrate an understanding of the team members' respective roles and preferences, and possibly also respect and a willingness to accommodate. It was most obvious in the teasing of the case manager. The social worker concluded: “it's a love-hate nature thing, just like you would tease your sibling. We know she's going to do what she does and so we just tease her because we know it's coming." A physician expressed how thankful he is that "you guys are doing this, I would be so lost [trying to figure out those CMS guidelines to find the most appropriate solution so that a patient does not feel like "we're pushing him out on the streets."]

Status hierarchy within the team. Another regular source of joking was the power differentials in the team. Physicians characteristically carry more status. The hospice and palliative care philosophy in general calls for egalitarian relationships, but those ideals can 
get diluted without efforts (James \& Field, 1992). There were significant efforts on the unit to empower the nurses. Team members frequently joked about who the most important member of the team is, as illustrated in the following example:

Nurse - Where is everybody? Can we start?

Hospice liaison - You are the most important person here, so I say yes!

Nurse (nodding and smiling) - Clearly I am!

Chaplain (jokingly) - I thought I was the most important person.

Hospice liaison - The both of you are!

\section{[Shared laughter]}

Some physicians played along, for example by demonstrating affection when somebody answered a question in their place or challenged their decision.

Case manager - It should be outpatient PT.

Physician (jokingly) - Right, who am I to change this?

\section{[Shared laughter]}

Social worker - You have two brains against you Doc on that one.

Physician (smiling) - All right, all right!

[Shared laughter] 
The team members were playfully challenging the traditional status hierarchy. The social worker responded to the physician's jocular claim to authority by siding with the case manager to get him to relinquish his power to decide. This lighthearted repartee affirms and at the same time challenges the power differentials between physicians and other team members, in a way that diminishes the potential for hierarchical tensions. Rituals of this type may in fact facilitate the experience of "power with/to" relationships rather than "power over" relationships (Follett, 1925; Aime, Humphrey, DeRue \& Paul, 2014). The social worker observed: "there isn't a lot of power struggles in the meeting. Regardless of the discipline, I feel like everyone can suggest things, and say things, and feel safe."

\section{Additional observations}

Joking cycles and to a lesser degree griping sessions were associated with a heightening of emotional energy in the room and typically more engaged conversations. The excitement that characterized the episodes was still evident in subsequent task-oriented turns. Team members were oriented toward each other, smiling and making eye contact. The conversations were animated. Those are all indicators of a positive, excited team mood (Lehmann-Willenbrock, Meyers, Kauffeld, Neininger \& Henschel, 2011). There was a clear correlation between the strong presence of joking and griping rituals in team meetings and the experience of a good meeting, characterized by collaborative talk and problemsolving rather than mere information reporting. Participants observed that at times the meetings felt more flat and the team as a whole more disjointed, citing humor and griping as one of the distinguishing factors between flat and engaging meetings. 
A physician in fact specifically identified joking as a critical factor for a good meeting, prior to my extending the research design to focus on griping and joking. He observed that banter could change the entire experience of a meeting, addressing both its energizing dimension in a heavy and challenging work context and its effect on interpersonal engagement.

As essential as [the interdisciplinary rounds] are, if members are busy with other things then it can lead to frustration in the meeting, you can see it on people's faces and you can feel it yourself, you feel frustrated yourself and so you can leave the rounds actually a little bit more drained than when you went in. If you go in and the banter's good you come out energized, you're a little happy and you've got a little pep to your day. [...] If we've had an engaged round then I may find that the interactions I have through nursing pages for the rest of the day, at least for a few hours while the after effects of the meeting persist, that those interactions may change a bit as well.

The team members were generally more cautious in their assessment of the value of griping. A physician warned that griping can "weigh people down a little" and advocated the use of "joke gripes" in team interactions to avoid depressed team mood and stimulate engagement. The case manager insisted: “you can't just complain, you have to do something constructive," while recognizing it is also sometimes appropriate to "just complain to complain." To team members, griping offers a valuable "pressure valve release" for those enduring troubles that they have to live with. They however resented complaints about team members, as "everybody is trying their best." Their comments signal 
the existence of particular rules for griping (Weeks, 2004). Ritualistic griping targeted primarily outsiders and the system's inadequacies. Playing up conflict was also associated with heightened emotional energy.

\section{Discussion}

In this study, I set out to explore the role of griping and joking in cross-boundary teams, an increasingly pervasive organizational context facing important emotional and relational challenges. Drawing on observational and interview data, I described the general qualities of griping and joking episodes, presented a typology of three griping forms and five joking forms, and documented their effects. Combining those findings with existing literature I develop below a view of griping and joking as identification rituals and tools for engagement in cross-boundary teams, before discussing my study's contributions to scholarship on cross-boundary teams and work on organizational joking and griping.

\section{A view of griping and joking as identification rituals}

The data from this study invite us to treat griping and joking patterns as identification rituals. ${ }^{2}$ Following the symbolic interactionist tradition and encouragement by scholars of humor and griping to look at evocative transactions (Couch, 1992) rather than individual statements and experiences, I have presented and analyzed griping and joking behaviors in terms of interacts and cycles (Weick, 1979). Those cycles or "little ceremonies" (Goffman, 1967, p.63) draw on a limited set of recurring outward- and inwardfocused themes: challenging work conditions, difficult clients, outside professionals, the team's own expertise and status, the team members' occupational roles, and the status 
hierarchy within the team. ${ }^{3}$ Those are recognizable themes capable of drawing team members to gripe, joke, sigh or laugh along and of establishing particular social realities in the process. Through the rituals, team members indeed do more than releasing individual frustration; they stress their commonalities (and thus prime a superordinate identity that transcends their differences) or bring into focus differences in perspectives, goals and status across occupational roles (and thus prime their distinct occupational identities).

Notably, through griping and joking about challenging work conditions and difficult clients, team members signal their commonalities of experiences and feelings in a stressful work environment that requires them to work with limited resources and to maintain a professional front of niceness. These are challenges that all team members face, independently of their roles. Their reinterpretation as collective challenges through griping and joking can foster a sense of connection (Coser, 1959; Katriel, 1985). Similarly, through griping about outside professionals and joking about the team's own expertise, team members highlight commonalities of values and status, which can bring about a sense of sameness and we-ness. Conversely, the presence of exculpatory turns in gripes about outside professionals signals differences of opinions and feelings between team members. Instead of playing up conflict to foster in-group solidarity, the team members manufacture ambivalence and encourage patience. This ambivalence towards outsiders may reflect the team's own struggles to paper over the contradictions that necessarily exist in the pursuit of conflicting priorities (Smith \& Berg, 1987). Also, when team members use role-oriented teases, they demonstrate an understanding of and respect for the team members' unique roles and goals, while simultaneously commenting on how challenging it is to 
accommodate those differences. Through playful inversions of the status hierarchy, team members recognize the reality of deeply ingrained power differentials, while leaving everyone feeling empowered.

Whether they stress commonalities or differences across occupational roles, both types of identification rituals are quite potent in enabling team engagement, as reflected in the excited team mood and open and animated conversations that typically follow their performance. The rituals derive their efficacy not only from the verbal communication and cognitive apprehension of commonality and difference, but also from emotional attunement and emotional energy recalibration. The griping and joking themes invoke work experiences that all team members share or can relate to. But beyond this salience effect, the rituals themselves create a shared experience: team members are 'having a moment', a moment that makes team feel closer, at least temporarily. The bodily co-presence during the rituals allows a rhythmic synchronization of emotional displays around the themes (Fine and DeSoucey, 2005; Katriel, 1985), which moves the team towards emotional attunement. Collins (2004) speaks of the transient production of high emotional energy and group solidarity through the performance of such symbolically charged activities. The joking and griping rituals that focalize commonalities across occupational roles unambiguously, albeit with a lesser intensity for griping rituals, produced the positive emotions of excitement and warmth that Collins associates with successful interaction rituals. Even the staging of conflict with outsiders produced heightened emotional energy, albeit negative emotional energy - the basis for negative solidarity. The rituals that bring inter-occupational differences into focus seemed to produce a more complex set of emotions, which 
nonetheless participates in the production of a favorably charged disposition towards team membership through the experience of respect and empowerment.

\section{Contributions to the literature on cross-boundary teams}

This explorative study of the role of griping and joking in cross-boundary teams makes several contributions to our understanding of the production of positive relational realities in cross-boundary teams. Scholars have only recently started to focus on the symbolic and relational work behind positive team emergent states, rather than merely documenting the importance of such states for cross-boundary work. So far, they have primarily emphasized team leaders' symbolic work. Building on the well-documented observation that humor and complaint can positively affect the quality of connections in the workplace, the present study suggests that griping and joking are critical mechanisms through which much needed socio-emotional bonds may be produced and reproduced in cross-boundary teams. The evidence presented here also stresses the fleeting nature of the socio-emotional effects of joking and griping rituals, and the need for their ongoing performances. It is not enough for team members to share some common ground, it must be “embraced through performances" (Fine \& Hallett, 2014, p. 1780), for the emotional charge carried by symbols decays if not revitalized through subsequent rituals (Collins, 2004). The study provides further evidence that team cohesion requires ongoing work in crossboundary teams - an organizational context rife with many affective and relational challenges that do not just go away if you have the right set-up or once the team has reached maturity. 
The distinction between griping and joking rituals that work through highlighting commonalities of experiences, beliefs and affect across occupational roles and those that work through recognizing and managing occupational differences in expertise, values and status is an important additional insight into the production of social cohesion in crossboundary teams through griping and joking. The rituals emphasized and infused with meaning and emotional energy both commonalities and differences in the team. My study supports the recent theoretical argument in cross-boundary team research that the simultaneous symbolic recognition of commonality and difference implied by multiple loci of social identification can improve connections within and to the team (MacPhail, Roloff \& Edmondson, 2009). Both categories of rituals can facilitate "engaged" interactions between team members, by respectively performing a supra-occupational community of common fate and values and displaying understanding and respect for occupational differences.

\section{Contributions to scholarship on griping and joking}

The present study goes beyond replicating what we know about the functional effects of humor and complaint in an overlooked organizational context. It enables a deeper understanding of how both communicative activities achieve their functional "cohesive" effects. The study builds on past research on the role of humorous and plaintive talk in reaffirming or creating social identities (e.g. Boxer \& Cortes-Conde, 1995; Mewburn, 2011), but methodologically and conceptually pays closer attention to the role of the nonverbal and affective details of both joking and griping in the production of socioemotional realities. Highlighting the role of the body and affect in the creation of social 
bonds complements the very verbal and cognitive image of social life that typically emerges from conversational analyses of humor and griping (Holmes and Marra, 2002), and emphasizes the role of griping and joking in bringing about emotional attunement and successful high-energy interactions in social groups (Collins, 2004).

This work also provides support and conceptual nuances to Cooper's (2008) theoretical argument that humor sharing and, by extension, griping foster group cohesion through affect reinforcement and perceived similarity. Indeed, my study reveals that different joking and griping rituals produce different kinds of emotional experiences and emotional energy - from positive to negative to ambivalent. In particular, by concurrently analyzing griping and joking, I found that despite similarities in structure and functionality, joking and griping still differ in the dynamics leading to their interactional and emotional consequences. Also perceived difference may not lead to feelings of group disconnection and the concomitant expression of team disengagement. My work shows that joking and griping rituals that focalize differences in perspectives, goals and status were associated with feelings of respect and empowerment, and translated into an excited, positive team mood. Hence, joking and griping may not only reduce the face threats of criticisms rooted in inter-occupational differences (Hatch, 1997; Weeks, 2004), but also encourage appreciation of those differences and instill patience.

\section{Limitations and future research}

This study inevitably has certain limitations - in particular, as with any single case study, there are limits to its empirical generalizability (Yin, 2009). My findings suggest a 
strong association between griping and joking and cross-boundary team cohesion and distinguish between multiple pathways to that association. Additional research should test the proposed association and address contingencies that might affect the occurrence and the power of joking and griping rituals separately and in combination in cross-boundary teams. I believe that the set of themes around which the rituals are built in my case may be recurrent themes in other cross-boundary teams in professional service organizations, or organizations relying on networked forms of knowledge work. Only a subset of the themes may appear in certain teams, and the list clearly is not exhaustive. I suggest that joking and griping exchanges around certain themes emerge and recur because they are functional to particular teams, which face specific challenges.

I am not proposing a deterministic theory, however, and the emergence of these functional "integrative" forms of griping and joking should be considered holistically. First, joking and griping rituals may not emerge or take hold in particular work contexts (Weeks, 2004), such as those dominated by a rationalist-professional discourse (Sturdy, Clark, Fincham \& Handley, 2008), or in teams where occupational cultures share very little common ground. Second, the social context, i.e. the nature of the social relations among those involved, may provide another contingency that affects the occurrence and functions of the joking and griping rituals (Robinson \& Smith-Lovin, 2001). For example, humor use increases with personal familiarity. Future research could explore the interaction of troubles talk and life talk. The priming of shared social identities through life talk may support bonding across occupational differences (DiBenigno \& Kellogg, 2014), in a way that may facilitate work-related troubles talk. Conversely, strong status differences may hinder the 
emergence of integrative forms of griping and joking rituals, in that distance can limit reciprocal humor (Coser, 1959) and constrain sympathy and understanding (Weeks, 2004). However, the substantial power differential between physicians and other staff in my case suggest that even strong-seeming boundaries can be managed through griping and joking rituals, leaving open the question of when the rituals may lead to a sense of empowerment and connection across status levels.

Finally, the present study does not fully explore the political dimension of joking and griping behaviors, though some of the rituals discussed clearly have a dissenting/resistance meaning. Future work could assess the extent to which the rituals that played up conflict with external others or that targeted the broader system may have a transformational effect on the target of the rituals (vs. merely acting as a safety valve with no consequences for the organization and the power structure in place). A multilevel analysis of humor and complaining that considers the broader political context of the team may yield additional important insights into the reproduction and transformation of complex systems and power structures. By illuminating how griping and joking influence interactions in cross-boundary team meetings, I hope to have spurred interest in, and provided a foundation for, more extensive investigations of the functions of mundane, expressive social activities in cross-boundary team life.

\section{Notes}

${ }^{1}$ There are effectively two main research agendas on joking and griping: a functionalist agenda that tends to associate those communicative behaviors with a set of 
positive managerial and organizational outcomes; and a critical agenda that places those communicative behaviors within a larger hegemonic power structure, as tactics for control or resistance (McFarland, 2004; Westwood \& Johnston, 2013). While I recognize that joking and griping can be politically laden and consequential activities, my primary focus in this paper is on the functional contributions that they can make towards team cohesion.

${ }^{2}$ Past research has likened griping and joking behaviors to Goffman's “interaction rituals" (e.g. Weeks, 2004). The concept of "identification rituals" builds on Goffman but foregrounds the conversational and affective identity work accomplished through the interaction rituals.

${ }^{3}$ Griping rituals tend to be organized around outward-focused themes, and joking rituals around inward-focused themes. Sources of trouble internal to the team can be laughed at, but not complained about. Complainables have to be externalized (Weeks, 2004). 


\section{References}

Aime, F., Humphrey, S., DeRue, D. S., \& Paul, J. B. (2014). The riddle of heterarchy: Power transitions in cross-functional teams. Academy of Management Journal, 57, $327-352$.

Boxer, D. (1993). Complaining and commiserating: A speech act view of solidarity in spoken American English. New York: Peter Lang.

Boxer, D., \& Cortes-Conde, F. (1995). From bonding to biting: Conversational joking and identity display. Journal of Pragmatics, 27. 275-294.

Collins, R. (2004). Interaction Ritual Chains. Princeton: Princeton University Press.

Collinson, D. (1988). Engineering humor: Masculinity, joking and conflict in shop floor relations. Organization Studies, 9, 181-199.

Coombs, R., \& Goldman, L. (1973). Maintenance and discontinuity of coping mechanisms in an intensive care unit. Social Problems, 20, 342-55.

Cooper, C. (2008). Elucidating the bonds of workplace humor: A relational process model. Human Relations, 61, 1087-1115.

Coser, R. (1959). Some social functions of laughter: A study of humor in a hospital setting. Human Relations, 12, 171-182.

Couch, C.J. (1992). Evocative transactions and social relationships. Studies in Symbolic Interaction, 13, 141-54.

Cronin, M.A., \& Weingart, L. R. (2007). Representational gaps, information processing, and conflict in functionally diverse teams. Academy of Management Review, 32, 761-773.

DiBenigno, J., \& Kellogg, K. (2014). Beyond occupational differences: The importance of cross cutting demographics and dyadic toolkits for collaboration in a US hospital. Administrative Science Quarterly, 59, 375-408.

Edmondson, A., \& Nembhard, I. (2009). Product development and learning in project teams: The challenges are the benefits. Journal of Product Innovation Management, $26,123-138$. 
Ellingson, L. (2003). Interdisciplinary health care teamwork in the clinic backstage. Journal of Applied Communication Research, 31, 93-117.

Faraj, S., \& Yan, A. (2009). Boundary work in knowledge teams. Journal of Applied Psychology, 94, 604-617.

Fine, G.A., \& DeSoucey, M. (2005). Joking cultures: Humor themes as social regulation in group life. Humor - International Journal of Humor Research, 18, 1-22.

Fine, G.A., \& Hallett, T. (2014). Group cultures and the everyday life of organizations: Interaction orders and meso-analysis. Organization Studies, 35, 1773-1792.

Follett, M. P. (1925). Power. Reprinted in H. Metcalf, H., \& L. Urwick (Eds.) (2004), Dynamic administration: The collected papers of Mary Parker Follett (pp. 72-95). New York: Routledge.

Gabriel, Y. (2000). Storytelling in organizations: Facts, fictions, fantasies. Oxford: Oxford University Press.

Gittell, J.H. (2006). Relational coordination: Coordinating work through relationships of shared goals, shared knowledge and mutual respect. In O. Kyriakidou, \& M. Ozbilgin (Eds.), Relational perspectives in organizational studies: A research companion (pp. 74-94). Cheltenham, UK: Edward Elgar Publishers.

Glaser, B., \& Strauss, A. (1967). The discovery of grounded theory. Chicago: Aldine.

Goffman, E. (1967). Interaction ritual: Essay on face-to-face behavior. London: Penguin.

Handelman, D. (1976). Re-thinking "Banana Time": Symbolic integration in a work setting. Urban Life, 4, 433-448.

Hatch, M. J. (1997). Irony and the social construction of contradiction in the humor of management team. Organization Science, 8, 275-288.

Hatch, M. J., \& Ehrlich, S.B. (1993), Spontaneous humor as an indicator of paradox and ambiguity in organizations. Organization Studies, 14, 4, 505-526.

Heaphy, E. and Dutton, J. (2008) Positive social interactions and the human body at work: Linking organizations and physiology. Academy of Management Review, 33, 137162.

Hibbert, D., Hanratty, B., May, C., et al. (2003). Negotiating palliative care expertise in the medical world. Social science \& medicine, 57, 277-288.

Holmes, J. (2000). Politeness, power and provocation: how humour functions in the workplace. Discourse Studies, 2, 159-185.

Holmes, J. \& Marra, M. (2002). Having a laugh at work: How humor contributes to workplace culture. Journal of Pragmatics, 34, 1683-1710. 
James, N., \& Field, D. (1992). The routinization of hospice: bureaucracy and charisma. Social Science and Medicine, 34, 1363-75

Katriel, T. (1985). 'Griping' as a verbal ritual in some Israeli discourse. Dialogue, 367-381.

Korczynski, M. (2011). The dialectical sense of humour: routine joking in a Taylorized factory. Organization Studies, 32, 1420-1040.

Kowalski, R. M. (2002). Whining, griping, and complaining: Positivity in the negativity. Journal of Clinical Psychology, 58, 1023-1035.

Lehmann-Willenbrock, N., Meyers, R. A., Kauffeld, S., Neininger, A., \& Henschel, A. (2011). Verbal interaction sequences and group mood: Exploring the role of planning communication. Small Group Research, 42, 639-668.

Li, S. (2004). "Symbiotic niceness:" Constructing a therapeutic relationship in psychosocial palliative care. Social Science and Medicine, 58, 2571-2583.

Lindenberg, S., \& Foss, N. (2011). Managing joint production motivation: the role of goal framing and governance mechanisms. Academy of Management Review, 36, 500525.

MacPhail, L.H., Roloff, K., \& Edmondson, A.C. (2009). Collaboration across knowledge boundaries within diverse teams: Reciprocal expertise affirmation as an enabling condition. In L.M. Roberts \& J.E. Dutton (Eds.), Exploring positive identities and organizations: Building a theoretical and research foundation (pp. 331-332). London: Psychology Press.

Marra, M. (2007). Humour in workplace meetings: Challenging hierarchies. In R. Westwood, \& C. Rhodes (Eds.), Humour, Work and Organization (pp. 139-157). Oxon and New York: Routledge.

Martineau, W. H. (1972). A model of the social functions of humor. In J. Goldstein, \& P. McGhee (Eds.), The psychology of humor (pp. 101-125). New York: Academic Press.

McFarland, D. (2004). Resistance as a social drama - A study of change-oriented encounters, American Journal of Sociology, 109, 1249-318.

Mewburn, I. (2011). Troubling talk: assembling the PhD candidate. Studies in Continuing Education, 33, 321-2.

Mitchell, R., Parker, V., \& Giles, M. (2011). When do interprofessional teams succeed? Investigating the moderating roles of team and professional identity in interprofessional effectiveness. Human Relations, 64, 1321-1343. 
Nembhard, I., \& Edmondson, A. (2006). Making it safe: The effects of leader inclusiveness and professional status on psychological safety and improvement efforts in health care teams. Journal of Organizational Behavior, 27, 941-966.

Oborn, E., \& Dawson, S. (2010). Learning across communities of practice: an examination of multidisciplinary work. British Journal of Management, 21, 843-858

Pinchot, G., \& Pinchot, E. (1993). The end of bureaucracy and the rise of the intelligent organization. San Francisco: Berrett-Koehler.

Ragin, C. (1994). Constructing social research: the unity and diversity of method. Thousand Oaks, CA: Pine Forge Press.

Robinson, D. T., \& Smith-Lovin, L. (2001). Getting a laugh: Gender, status, and humour in task discussions. Social Forces, 80, 123-158.

Rodrigues, S., \& Collinson, D. (1995). Having fun? Workplace resistance and humour in Brazil. Organization Studies, 16, 739-768.

Romero, E., \& Pescosolido, A. (2008). Humor and group effectiveness. Human Relations, $61,395-418$.

Schwartzman, H. B. (1989). The meeting: Gatherings in organizations and communities. New York: Plenum.

Seckman, M.A., \& Couch, C.J. (1989). Jocularity, sarcasm, and social relationships. Journal of Contemporary Ethnography, 18, 327-44.

Smith, K. K., \& Berg, D. N. (1987). Paradoxes of group life: Understanding conflict, paralysis, and movement in group dynamics. San Francisco: Jossey-Bass.

Sturdy, A., Clark, T., Fincham, R. and Handley, K. (2008). Management consultancy and humor in action and context. In S. Fineman (Ed.), The emotional organization (pp. 134-153). Oxford: Blackwell.

Terrion, J. L., \& Ashforth, B. (2002). From "I" to "we": The role of putdown humor and identity in the development of a temporary group. Human Relations, 55, 55-88.

Van der Vegt, G., \& Bunderson,, J. (2005). Learning and performance in multidisciplinary teams: The importance of collective team identification. Academy of Management Journal, 48, 532-547.

Weeks, J. (2004). Unpopular culture: The ritual of complaint in a British bank. Chicago: The University of Chicago Press.

Weick, K.E. (1979). The social psychology of organizing. New York: McGraw-Hill, Inc.

Westwood, R., \& Johnston, A. (2013). Humor in organisation: From function to resistance. Humor - International Journal of Humor Research, 26, 219-247. 
Wittenberg-Lyles, E.M. (2005). Information sharing in interdisciplinary team meetings: An evaluation of hospice goals. Qualitative Health Research, 15, 1377-1391.

Yin, R. (2009). Case study research: Design and methods (4th edition). Newbury Park, CA: SAGE Publications. 